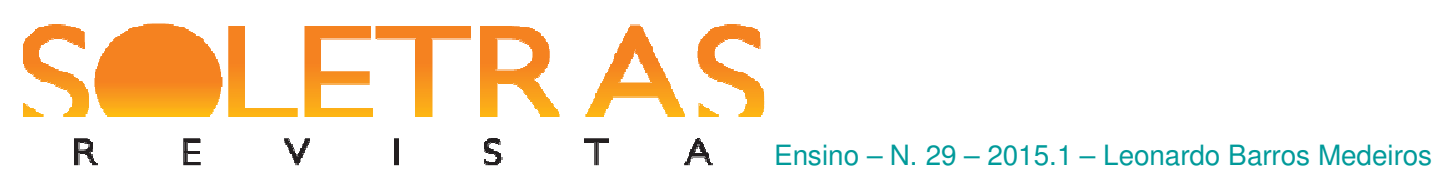

\title{
As atitudes de leitura do Projeto Surpreenda-me: Para uma didática da intermidialidade nas aulas de literatura
}

\author{
Leonardo Barros Medeiros ${ }^{1}$ \\ Universidade de Coimbra
}

Resumo: A partir de uma breve análise dos produtos realizados por alunos de uma escola pública da Baixada Fluminense - em específico três - pretendemos trazer para o debate acadêmico uma proposta de atividade em que se priorizou a produção de conhecimento discente atrelada às mídias. O Projeto Surpreenda-me possuía a proposta de tornar os alunos os agentes principais de transmissão de saberes de forma atraente e dinâmica. Ação que proporcionou novas formas de conceber o texto literário interagindo com outras mídias e suportes textuais como forma de reapropriação e ressignificação dos conteúdos. Quais os modos possíveis de aproximação da literatura na contemporaneidade? De que forma o professor transforma o aluno em agente de ensino? Quais as estratégias de apoio a leitura disponíveis para o professor? Quais as formas de apropriação da literatura que proporcionam uma efetiva recepção e circulação do texto literário na escola? Como transformar a escola num espaço propício para trocas literárias? Como criar uma comunidade de leitores em sala de aula? De que forma que as mídias contribuem para o ensino? De que maneira as novas mídias geram outras leituras? Essas e outras questões nortearam o Projeto Surpreenda-me, foco da pesquisa, e servem domo diretrizes para a tessitura do artigo.

Palavras-chave: Ensino de Literatura. Educação Pública. Intermidialidade.

Aos surpreendentes alunos do Colégio Técnico da UFRRJ:

\begin{abstract}
Acho que o quintal onde a gente brincou é maior do que a cidade. A gente só descobre isso depois de grande. A gente descobre que o tamanho das coisas há que ser medido pela intimidade que temos com as coisas. Há de ser como acontece com o amor. Assim, as pedrinhas do nosso quintal são sempre maiores do que as outras pedras do mundo. Justo pelo motivo da intimidade.
\end{abstract}

Manoel de Barros

Sabemos que o ensino da literatura é um campo atravessado por representações sociais e culturais e que o professor é o agente mediador entre o texto e o aluno, cumprindo escolhas literárias e conduzindo sua turma pelos textos. Dessa forma, conceber o espaço escolar como

\footnotetext{
${ }^{1}$ Graduado em Letras pela Universidade Católica de Petrópolis com mestrado em Literatura Brasileira pela Universidade Federal do Rio de Janeiro e doutorando em Literatura Brasileira, com bolsa CAPES, na Universidade de Coimbra. Foi Professor Assistente Convidado de Literatura Brasileira na Faculdade de Letras da Universidade de Coimbra, foi professor substituto de Literatura Brasileira na Universidade Federal Rural do Rio de Janeiro e é, junto com Marcos Pasche, organizador do livro de ensaios Hoje é dia de hoje em dia: literatura brasileira da primeira década do século XXI. E-mail: leonardoletras@gmail.com.
}

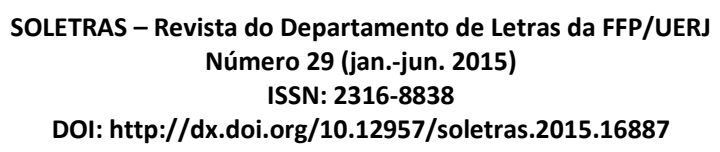


$\begin{array}{llllllll}\mathbf{R} & \mathbf{E} & \boldsymbol{V} & \mathbf{I} & \mathbf{S} & \mathbf{T} & \mathbf{A} & \text { Ensino-N. 29-2015.1-Leonardo Barros Medeiros }\end{array}$

uma oficina do texto, transformando-o numa entidade dinâmica e viva, de forma que seja mais apreensível e prazerosa pela comunidade, é o papel do educador comprometido com uma educação que vai além dos programas e dos muros da escola.

Segundo as Orientações Curriculares Nacionais, é um dos deveres do professor com o educando, especificamente no ensino de literatura, de:

Formar para o gosto literário, conhecer a tradição literária local e oferecer instrumentos para uma penetração mais aguda nas obras - tradicionalmente objetivos da escola em relação à literatura - decerto supõem percorrer o arco que vai do leitor vítima ao leitor crítico (2006, p. 69).

Esse percurso é complexo e pleno de alternativas que são mais ou menos atraentes para os caminhantes. Contudo, o trajeto deve ser menos cansativo possível de tal forma que não se percam pelo caminho os futuros leitores críticos. Todavia, não há guias, mapas ou roteiros para essa prática; há somente o entusiasmo e o desejo de formar leitores expressivos, algo que todo professor já traz em sua bagagem.

Torna-se uma tarefa quase hercúlea e sem modelos prontos implementar essa concepção de ensino/aprendizagem. Porém, não é impossível. Veremos nesse trabalho a proposta de um projeto realizado entre em 2013 com alunos do Ensino Médio numa escola pública em que a concepção do texto como objeto de verbalização foi entendida como primícias para o ensino de literatura.

Quais os modos possíveis de aproximação da literatura na contemporaneidade? De que forma o professor transforma o aluno em agente de ensino? Quais as estratégias de apoio a leitura disponíveis para o professor? Quais as formas de apropriação da literatura que proporcionam uma efetiva recepção e circulação do texto literário na escola? Como transformar a escola num espaço propício para trocas literárias? Como criar uma comunidade de leitores em sala de aula? De que forma que as mídias contribuem para o ensino? De que maneira as novas mídias geram outras leituras?

Essas questões nortearam o projeto e servirão, em conjunto com outras, de orientação para a tessitura do trabalho em que se propõe, além de apresentar o projeto, analisar os resultados decorrentes, problematizando com teóricos que já se propuseram a debruçar sobre o ensino de literatura.

\section{O Projeto Surpreenda-me}




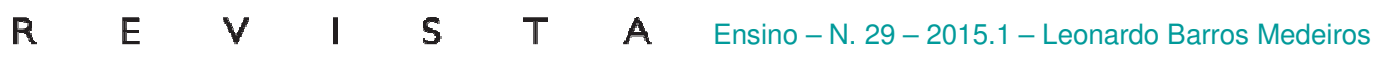

Para que haja uma produtiva articulação entre o ensino da literatura e o prazer pela leitura é necessário que o professor esforce-se para construir uma prática docente que expanda seu espaço e tempo além das paredes da sala de aula, ressignificando novos contextos e ambientes de criação verbal, conforme apontam Bernardes e Mateus (2013, p. 61):

Dimensão fundamental do saber do professor que deve ser reforçada num programa de revitalização do ensino da literatura é a da utilização dos contextos. Ao falarmos de contextos, nesse âmbito, convocamos necessariamente uma antiga parceria entre os saberes de natureza especificamente literária e conhecimentos inscritos noutros campos, que, podendo ser considerados exteriores ao fenômeno literário na sua essência estética, lhe são adjacentes na sua qualidade de processo comunicativo, englobando o conjunto de circunstâncias a que atos de criação, circulação e recepção literária não são alheios.

Pensando dessa maneira é que se planejou o projeto Surpreenda-me em que os alunos tornavam-se os agentes principais de transmissão de saberes de forma atraente e dinâmica. Ação que proporcionou novas formas de conceber o texto literário interagindo com outras mídias e suportes textuais como forma de reapropriação e ressignificação dos conteúdos.

O projeto consistia na apresentação dos conteúdos abordados no bimestre, de acordo com o planejamento e de forma criativa, e que suscitaria novas leituras. Ou seja, ao final de cada bimestre, como parte de avaliação, era solicitado que os alunos em grupos fizessem uma apresentação sobre alguma obra, autor ou temática em formato de seminário. Dessa forma, eles teriam que apresentar a estrutura da obra, características do autor, enredo, a poética da qual o texto fazia parte, análise dos personagens, enfim, os elementos básicos de uma análise literária baseado no tema por eles abordado. Cada grupo dispunha de 25 minutos para apresentar o seu trabalho; os primeiros 15 minutos seriam destinados à apresentação dessa primeira parte.

Além de essa parte ser apresentada oralmente, o grupo entregaria a proposta devidamente estruturada e escrita como parte da avaliação bimestral. Essa avaliação consistia então numa parte com as notas da prova final, em que eram abordados os conteúdos explorados em classe ao longo do bimestre, e a outra uma síntese, resultante da apresentação oral com a escrita.

Cabe ressaltar que a atividade era apresentada no último dia de aula do bimestre, antes da prova final e que era proposta no primeiro dia junto com a apresentação da ementa bimestral da disciplina. Isso se torna importante, pois o professor consegue durante o período 
$\begin{array}{llllllll}\mathbf{R} & \mathbf{E} & \mathbf{V} & \mathbf{I} & \mathbf{S} & \mathbf{T} & \mathbf{A} & \text { Ensino-N. 29-2015.1-Leonardo Barros Medeiros }\end{array}$

letivo trabalhar de forma expressiva os conteúdos, dando suporte para os alunos conseguirem realizar a atividade, sem maiores dificuldades dentro do prazo já acordado entre as partes.

A segunda parte, que originou o nome do projeto, realizava-se nos últimos minutos da apresentação em que os alunos proporcionaram uma nova maneira de abordar o tema que lhes fora proposto para análise. Por outras palavras, o professor queria ser surpreendido com as interpretações e os novos olhares dos alunos diante do objeto abordado. Esse componente da atividade não recebia nenhuma orientação do professor e por esse motivo não se tornava parte da avaliação, sendo assim a motivação para sua realização era extrínseca à prática valorativa de uma prova.

A escolha por não valorar esse segmento da atividade faz com que os alunos sintam-se mais seguros em sua realização e a façam de forma espontânea e gratuita, ocasionando assim uma atividade que, em sua concepção, priorizava a fruição da leitura. Essa prática permitia que os alunos pudessem trabalhar com os saberes próprios construídos ao longo da experiência individual, incentivando a solidificação de suas identidades culturais.

Ao analisar os produtos da atividade, temos que considerar alguns fatores que contribuíram para transformar o texto em movimento, influenciando no processo e no resultado final, tais como: a memória dos alunos e suas emoções; as expectativas da apresentação; as tecnologias utilizadas para a construção dos trabalhos; o recorte das obras analisadas; o ângulo individual. Dessa forma o texto era inserido num processo de transformação e de recodificação.

Certamente o aluno ao realizar essa etapa introduzia em sua produção vivências cotidianas que auxiliaram na realização da tarefa; característica que traz à baila um dos encaminhamentos sobre o ensino da literatura direcionado por Marisa Lajolo (1993, p. 16):

$A$ inscrição do $e$ no texto, no $e$ do cotidiano do aluno, entendendo que este cotidiano abrange desde o mundo contemporâneo (no que essa expressão tem, intencionalmente, de vago e de amplo) até os impasses individuais vividos por cada um, nos arredores da leitura de cada texto.

Compreendemos que no ato de dar voz aos alunos propiciamos a autoria e transmissão de conhecimentos que, para muitos, é uma função exclusiva do professor. De tal forma que eles tornam-se o centro irradiador do processo educativo dentro de uma ação recíproca de transmissão e aprendizagem. Tal dialética produz uma alteração na forma em que os conteúdos são abordados em sala de aula, realizando um movimento qualitativo na interação entre aluno, texto e professor. 


\section{$\begin{array}{llllllll}\mathbf{R} & \mathbf{E} & \boldsymbol{V} & \mathbf{I} & \mathbf{S} & \mathbf{T} & \mathbf{A} & \text { Ensino-N. 29-2015.1-Leonardo Barros Medeiros }\end{array}$}

A experiência literária preconizada no projeto Surpreenda-me pressupõe uma visão da literatura como possibilidade de entrada na vida prática dos alunos, desafiando-os a interpretações das obras baseadas em sua própria cosmovisão. De certa forma é uma maneira de valorizar seus conceitos e vivências discentes no espaço escolar, conforme aponta Regina Zilberman (2000, p. 97):

A leitura pode exercer sua habilidade de liberar os indivíduos. No âmbito da
escola, equivale a compreendê-la como atividade fundada no texto literário,
cujo caráter, dialógico de nascença, impõe ao leitor um segundo diálogo, de
que se originará talvez um terceiro, a manifestação textual que o leitor for
capaz de gerar.
O saber facultado pela leitura concretiza-se na capacidade, individual e
intransferível, de entender o mundo do texto, imitação direta ou alegórica do
universo em que vivemos.

Destarte os resultados apresentados pelos alunos tornam-se imitação da imitação, pois é a reinterpretação dos alunos a partir da tradução do mundo realizado pelos autores. Algumas produções que essas releituras geraram ao longo de três bimestres transverteram os gêneros de origem, adaptando as obras analisadas para outros, realizando rupturas nos suportes e adequando-as aos novos meios, sem perder a essência e as ideias vinculadas em sua origem.

Percebemos isso quando os alunos ao realizar a apresentação da obra em análise recorrem a diversas manifestações artísticas, tais como: a fotografia, a música, a poesia, a fanfiction, a adaptação para teatro, para um programa televisivo sensacionalista, para draw my life ou para cinema e ao videogame. Todos esses suportes midiáticos foram utilizados pelos alunos em suas apresentações dando um novo corpo, externo aos livros, para a literatura.

O perfil do docente que a escola assinala no seu Projeto Político Pedagógico, documento de 2010, aponta para o papel de mediador e estimulador do processo de ensinoaprendizagem. A primeira concepção de educação presente nesse documento aponta enfaticamente para uma educação voltada para a emancipação humana:

O ser humano precisa ser percebido e valorizado em suas múltiplas manifestações e tais expressões podem revelar-se na ética, estética, cognição, afetividade e psicomotricidade.

$\mathrm{Na}$ ética, o compromisso com o interesse comum deve sinalizar a formação esperada.

$\mathrm{Na}$ estética, a oportunidade e a valorização de diferentes manifestações artísticas podem estimular a sensibilidade indispensável ao trato da forma e da emoção na ação humana (2010, p. 5).

Visando essa atitude emancipatória de trabalho com a obra literária, o projeto permitiu aos alunos dialogarem com os textos, recuperando os conhecimentos anteriormente 


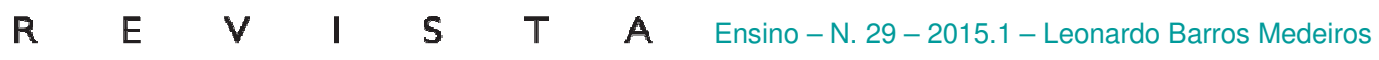

apresentados e adicionando o desejo de adquirir novos com uma leitura atraente. Sobre esse processo de reapropriação da leitura Tânia Rösing (2003, p. 23) diz que:

Ao ser desencadeado o processo de leitura, o ato de ler tende a transformarse num ato contínuo cuja continuidade depende de aspectos subjetivos, da intenção e da atitude. A compreensão do texto está diretamente ligada à satisfação dos objetivos do leitor. Normas subjetivas, intenção de ler e atitude em relação à leitura dependem, na estrutura social e no contexto ambiental, das crenças sobre as expectativas de outros sobre a motivação de cada um para adaptar-se a essas expectativas, contradizê-las, entrar em conflito com as mesmas e das crenças sobre os resultados da leitura trazidos a pessoas que desenvolvam uma atitude de leitura.

Nas estratégias de leitura adotadas pelos alunos, brevemente apontadas anteriormente, estão incutidas suas escolhas e atitudes de leitura diante do texto literário. Escolhemos três dessas posturas para olharmos com maior acuidade e mediação crítica: poesia, fanfiction e videogame. A escolha dos objetos de análise não foi aleatória, mas, sim, por serem produções de alunos que estavam num mesmo ciclo e que trabalhavam numa mesma temática.

Conceitos como signo linguístico, intertextualidade, paráfrase, paródia, emissor, receptor, sintagma ou as convenções poéticas como a versificação, formas fixas, esquema rímico, metrificação e até mesmo as figuras de linguagem são conteúdos que ao longo da disciplina de literatura no Ensino Médio, desde o primeiro ano, tornam os alunos mais íntimos ao ponto de quando chegarem ao último ano conseguirem realizar uma simples análise textual. Essa capacidade de trabalhar em nível de maior abstração nesse momento conflui também para que na produção escrita reflita esses conceitos.

O poema A seca e algumas vidas, inspirado pelo romance Vidas Secas, de Graciliano Ramos e escrito por Larissa da Silva Gomes, é resultado e reflexo desse processo de amadurecimento provocado pelas leituras e pela capacidade cognitiva do aluno de transpor essa densa narrativa para esse novo suporte genológico. Cabe ressaltar que o poema foi publicado no número 40 do semanário Rural Semanal de 2013, esse periódico é um boletim oficial da Universidade Federal Rural do Rio de Janeiro, e que hoje sua autora está cursando a Faculdade de Letras da Universidade Federal do Rio de Janeiro.

Algumas ideias centrais abordadas por Graciliano ao longo do romance foram condensadas no poema em alguns versos concorrendo para que o sentido global da obra não esmoreça, ganhando novos contornos. Eis alguns exemplos:

a) a descrição do personagem: "Havia um nordestino chamado Fabiano / Que vivia mal, feito cão sem dono"; 
$\begin{array}{llllllll}\mathbf{R} & \text { E } & \mathbf{V} & \mathbf{I} & \mathbf{S} & \mathbf{T} & \mathbf{A} & \text { Ensino-N. 29-2015.1-Leonardo Barros Medeiros }\end{array}$

b) a condição migratória do retirante: "Migrava em busca de um lugar" ou "Novamente tiveram que partir / Em busca de novo lar";

c) a fome incessante: "A fome era feroz / Não dava para esperar";

d) o flagelo da seca: "A seca retomava, sem jamais esperar";

e) a desonestidade do patrão: "O salário vinha sempre com uma parte a faltar" ou "Saia de minha terras, seu safado / Não te quero mais lá";

f) a desumanização dos personagens: "Essas vidas / Que eram parte do cenário";

g) a dissipação de afetos: "Pena que o papagaio virou jantar" ou "Baleia, a cachorrinha / Fabiano teve que sacrificar";

h) a condição social: "Sua família , muito pobre";

i) o diálogo interior: "É... agora acho que nossas vidas entram no lugar".

Contudo essas temáticas convergem no poema de forma concisa sem quebras da fluição textual tornando-o unitário e enxuto. Essa prática de produção textual durante o Ensino Médio não é bem valorizada em detrimento ao ensino de textos dissertativos com a finalidade preparatória para os exames externos de acesso ao nível superior. Ao lado desse gênero, outro que ganha espaço com os jovens, o fanfictions ou simplesmente fanfic, ainda não adentrou os muros da escola.

As manifestações do leitor diante da obra literária são diversas em sua totalidade mas no projeto em análise está em voga as produções decorrentes da leitura literária. O conto fanfic intitulado A maldição de São Bernardo, baseado na leitura da obra São Bernardo, também de Graciliano Ramos, trata-se de um novo final para o romance estabelecendo um diálogo explícito com a obra original.

Sobre esse gênero, Padrão (2007, p. 2) diz que:

Por fanfiction estamos nos referindo ao hobby literário cujo objetivo é escrever histórias baseadas em universos ficcionais - personagens, cenários e acontecimentos - criados por terceiros. Na grande maioria dos casos, a principal inspiração dos escritores de fanfiction são histórias lançadas por produtos da indústria cultural, como livros, filmes, desenhos animados, quadrinhos e seriados de TV. Os adeptos desse passatempo são pessoas que, por opção, transcenderam o status de meros consumidores dessas histórias, expandindo seu relacionamento com esse universo ao recriá-lo e/ou ampliálo em seus próprios contos.

No fanfic o pio da coruja é o mote que gera toda a narrativa e a causa da desgraça do protagonista, o mesmo de Graciliano: "A chama da vingança ardeu com ainda mais poder, e o 
$\begin{array}{llllllll}\mathbf{R} & \mathbf{E} & \mathbf{V} & \mathbf{I} & \mathbf{S} & \mathbf{T} & \mathbf{A} & \text { Ensino-N. 29-2015.1-Leonardo Barros Medeiros }\end{array}$

espírito das aves fizeram bem mais que quebrar vidro". Dessa forma a produção textual concebida não se configura em apenas uma resposta opinativa sobre São Bernardo ou em um resumo de seu enredo, mas, sim, em uma nova mensagem independente criada intertextualmente.

A alusão realizada na fanfiction remete ao vazio existencial de Paulo Honório traduzindo pela sua personalidade e remete aos seus últimos dias: "Já não restava mais nada na vida de Paulo". A ambientação convoca os leitores a entrarem numa atmosfera em que as fronteiras do real não possuem contornos definidos realizando, assim, uma leitura pela perspectiva fantástica de São Bernardo, como vemos nos excertos: "Na penumbra da noite", "uma terra sagrada", "esse paraíso". Essa é uma postura que percebemos desde a leitura do título, A maldição de São Bernardo, que pretende justificar as desgraças ocorridas na vida do protagonista.

A escolha pelo gênero implica diretamente nas novas tendências estilísticas autônomas em que os jovens não são apenas expectadores mas também produtores culturais. Nesse contexto contemporâneo as mídias digitais exercem forte influência e ao lado dos jogos eletrônicos envolvem os jovens pela interatividade das narrativas ali presente.

Nesse cenário é que se inscreve a última produção aqui apresentada: o jogo $O$ quinze the game. Baseado na obra de Rachel de Queirós, O quinze, o jogo traz para o cenário digital as agruras provocadas pela seca, enfocado somente na família de Chico de Bento. Sua jornada para Fortaleza, a morte dos filhos, ou seja, a peregrinação do protagonista é transposta para o jogo a partir da interação dos personagens.

A expressão do enredo da autora ultrapassa o papel e surge na tela em formato de game com o intuito de ser facilitador do aprendizado e plataforma de conhecimento. No entanto, a mensagem transmitida por Rachel de Queirós está enraizada no jogo resultando numa consolidada interface, promovendo a transmissão de conteúdos de forma interativa entre o jogador/leitor e o jogo/livro.

Sabemos que para finalizar esse tipo de enredo é necessário participação direta do jogador ao realizar as ações decorrentes do jogo. Nessa dialética, o jogador torna-se autor a partir do momento em que escolhe as ações, optando ou não pela sua realização, que o direcionam dentro do jogo para o desfecho do enredo. Sendo assim, o canal de comunicação é realizado por meio da interatividade entre o suporte e o usuário trazendo possibilidades e perspectivas narrativas para a $O$ quinze. 
$\begin{array}{llllllll}\mathbf{R} & \mathbf{E} & \mathbf{V} & \mathbf{I} & \mathbf{S} & \mathbf{T} & \mathbf{A} & \text { Ensino-N. 29-2015.1-Leonardo Barros Medeiros }\end{array}$

No jogo a interação não é apenas interpretativa, tal como realizamos ao ler a obra, mas, sim, de forma concreta em que podemos transformar o enredo inserindo novos desfechos para as cenas apresentadas de forma em que o usuário apropria-se do lugar de autor. A transmidialidade presente na proposta apresentada é reflexo da cultura jovem na sociedade. Por esse motivo, deve ser convidada a permanecer na escola como apoio para as metodologias e para que os alunos sintam-se parte do processo de ensino.

A transposição genológica pressupõe o conhecimento pormenorizado da obra de origem e da estrutura do novo suporte midiático. Essa relação contribui para que a produção não se torne apenas uma conversão de feição simplória e artificial que deforma o texto original. Algo que podemos observar nas produções em que a relação dos leitores da obra com os escritores/produtores lança novas interações com os atuais leitores. Rettenmaier (2003, p. 53) sobre esse contato diz que:

A noção intersubjetiva faz do texto também um sujeito que oferece diálogo
com outro sujeito, o leitor, reconstituindo-se ambas as partes, texto e leitor,
como elementos plurais, compostos de outras leituras: o leitor, pela
biblioteca de sua compreensão e de sua teoria de mundo; o texto (tomado no
sentido mais amplo, como enunciação verbal, visual, sonora), pelas inúmeras
fontes e a outras manifestações textuais da cultura nele observáveis.

Esse diálogo expressivo ressignifica o processo de aprendizagem dando novos suportes para o trabalho do professor com a literatura no ambiente escolar.

Percebemos que esse novo olhar para as mídias reflete diretamente no processo educativo, em que os alunos estão cada vez mais conectados aos novos suportes tecnológicos e, de maneira ampla, a escola parece estar ainda estagnada na era do giz e lousa. Para Canclini (2005, p. 237) “a conjugação de telas de televisão, computadores e videogames está familiarizando as novas gerações com os modos digitais de experimentar o mundo, com os estilos e ritmos de inovação próprios destas redes". Dessa forma, o ensino de literatura tem como grande aliado as novas mídias e suas utilizações na sala de aula contribuem para aproximação do cotidiano discente com a disciplina. Essa coligação desenvolve novos formatos de leitura e proporcionam que a fruição literária penetre no espaço escolar.

\section{Considerações finais}

Para que o processo educativo seja eficaz é necessário que o professor compreenda que o procedimento de transmissão de saberes não é apenas seu único papel e que o conteúdo 
$\begin{array}{llllllll}\mathbf{R} & \mathbf{E} & \boldsymbol{V} & \mathbf{I} & \mathbf{S} & \mathbf{T} & \mathbf{A} & \text { Ensino-N. 29-2015.1-Leonardo Barros Medeiros }\end{array}$

a ser transmitido deva ser significativo. Atuar nessas condições requer conhecer que a experiência individual de cada aluno contribui expressivamente para a aquisição de conhecimentos próprios e dos demais colegas, numa constante dialética entre os saberes escolares e pessoais.

As amostras expostas no trabalho são representantes de diversos resultados em que novas propostas de abordar o texto literário foram realizadas de forma lúdica e inovadora potenciando a fruição literária. Essas surpresas que os professores recebem ao longo de sua jornada é o que os recarregam para ajudar a construir sujeitos que, além de críticos, inquietos, questionadores, sejam indivíduos conscientes de que sua interação com o mundo dá-se também por meio dos textos e das palavras.

A concepção do Projeto Surpreenda-me para as aulas de literatura não pretende extinguir o texto da sala de aula, mas sim, propor alternativas pedagógicas para o ensino da disciplina num contexto em que as mídias e a autonomia discente contribuem para o processo de aprendizagem. Cabe à cada docente encontrar uma metodologia que envolva uma relação intermidiática com os conteúdos programáticos que possa contribuir para o processo ensinoaprendizagem.

Tomemos emprestado o exemplo da borboleta que antes de seu primeiro voo passa por um processo de transformação em que ela se fecha em si para ressurgir mais tarde, bela: eis aí a metamorfose. O ciclo da vida desse inseto nada mais é do que uma transformação em sua forma, em sua estrutura e em seus hábitos. Existem até lagartas que são venenosas, porém, depois do casulo, abandonam seu formato, ganham asas e encantam o mundo. Surge aqui um paradoxo: ao mesmo tempo em que há uma descontinuidade há uma permanência da vida.

Esse processo também deve ocorrer nas salas de aula: a permanência de conteúdos que ressignifiquem o cotidiano dos alunos. Nesse momento, no ato da transposição literária, percebemos o amadurecimento leitor que os envolvidos no projeto passaram para que obtivessem êxito na apresentação. Outra importante transformação na vida de leitores é a liberdade de escolhas, outra vez tomamos aqui a imagem da borboleta em seu voo sob o céu infinito que não possui um rumo certo. Petit (2008, p. 26), sobre a liberdade na imaginação dos leitores, nos diz que:

Não se pode jamais estar seguro de dominar leitores, mesmo onde os diferentes poderes dedicam-se a controlar o acesso aos textos, lhes dão outro significado, mudam o sentido, interpretam à sua maneira, introduzindo seus desejos entre as linhas: é toda a alquimia da recepção. Não se pode jamais controlar o modo como um texto será lido, compreendido e interpretado. 


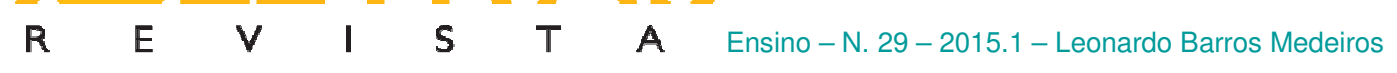

Ao encontro de Petit é que ressaltamos os resultados do projeto. Os envolvidos transformaram-se em leitores conscientes e agora podem voar mais alto e essa metamorfose, ocasionada pela leitura, diz respeito ao conhecimento de mundo, na sua forma de percepção e interação.

Acreditamos que esse procedimento deve ser único e sem métodos prontos por envolver três fatores distintos: o professor, os alunos e a escola. Nesse contexto, o professor não só ensina como também potencia o desenvolvimento intelectual dos seus alunos valorizando suas competências e habilidades individuais dos reais sujeitos da aprendizagem, levando a literatura para além dos muros da escola, surpreendendo-se.

\section{Referências bibliográficas:}

BERNARDES, José Cardoso et MATEUS, Rui Afonso. Literatura e ensino do português. Lisboa: Fundação Francisco Manuel dos Santos, 2013.

CANCLINI, Nestor García. Diferentes, desiguais e desconectados: mapas da interculturalidade. Rio de Janeiro: UFRJ, 2005.

CTUR. Projeto Político Pedagógico. Disponível em: http://www.ctur.ufrrj.br/Documentos/PPP2011.pdf. Acesso em 01 jun. 2013.

LAJOLO, Marisa. Do mundo da leitura para a leitura do mundo. São Paulo: Ática, 1993.

MEC. Orientações Curriculares Nacionais. Disponível em: http://portal.mec.gov.br/seb/arquivos/pdf/book_volume_01_internet.pdf Acesso em: 23 abr 2013.

PADRÃO, Márcio. Ascensão de uma subcultura literária: ensaio sobre fanfiction como objeto de comunicação e socialização. In: Ciberlegenda. Niterói, RJ: UFF, 2007. Disponível em: http://www.uff.br/ciberlegenda/ojs/index.php/revista/article/view/173. Acesso em 28 abr. 2014.

PETIT, Michele. Os jovens e a leitura: uma nova perspectiva. São Paulo: Editora 34, 2008.

RETTENMAIER, Miguel. Por um leitor indócil In: ROSING, Tânia. Práticas leitoras para uma cibercivilização IV: vivencias interdisciplinares e multimídias de leitura. Passo Fundo: UPF, 2003, p. 43-59.

ROSING, Tânia. A (des) construção da construção. In: ROSING, Tânia. Práticas leitoras para uma cibercivilização IV: vivencias interdisciplinares e multimídias de leitura. Passo Fundo: UPF, 2003, p. 13-29. 


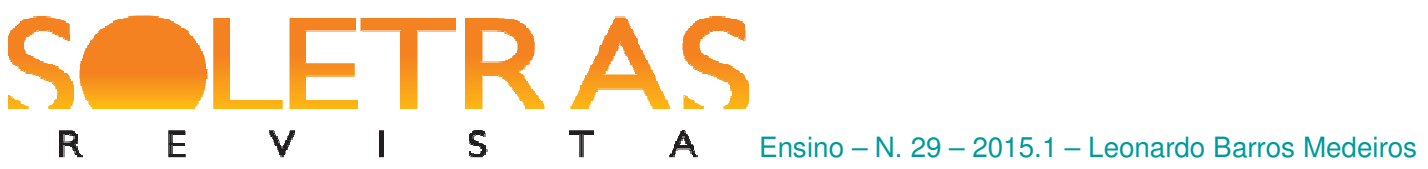

ZILBERMAN, Regina. Leitura e produção do conhecimento. In: Didática de língua e da literatura. Vol I, 1998. Universidade de Coimbra. Coimbra: Almedina, 2000.

\title{
Reading acts of the Surpreenda-me Project: towards a didates of the itermidiality in literature classes
}

\begin{abstract}
From a brief analysis of the products made by students from a public school in the Baixada Fluminense - in particular three - we intend to bring to the academic debate a proposed activity in which prioritized the production of student knowledge linked to the media. The Surprise-me Project had a proposal to make the students the principal agents of transmission of attractive and dynamic knowledge. This proposal provided new ways of conceiving the literary text interacting with other media and textual media as a way of reappropriation and reinterpretation of the contents. What are the possible ways to approach literature in contemporary society? How the teacher becomes the student in education agent? Which reading support strategies are available to the teacher? What forms of appropriation of literature provide an effective reception and literary text circulation in school? How to turn the school into a space conducive to literary exchanges? How to create a community of readers in the classroom? How the media contributes to the teaching? How new media generate further reading? These and other questions guided the Surprise-me Project, research focus, and serve dome guidelines for the fabric of the article.
\end{abstract}

Keys words: Literature Teaching. Public Education. Intermedialy.

Recebido em: 25 de junho de 2015.

Aprovado em: 10 de agosto de 2015. 


\section{Anexos}

Anexo I - Poesia

\section{A seca e algumas vidas}

Larissa Gomes

Havia um nordestino chamado Fabiano

Que vivia mal, feito cão sem dono

Sua família, muito pobre,

Migrava em busca de um lugar

Em que a seca permitisse

Que suas vidas pudessem continuar

$\mathrm{O}$ rio havia secado

Água em nenhum lugar

Mas, olhe lá, uma fazenda

Vamos nos abrigar

Pena que o papagaio virou jantar

Antes mesmo de chegarem lá

A fome era feroz

Não dava pra esperar

$\mathrm{Na}$ nova moradia, cultivaram, prosperaram

É... agora acho que nossas vidas entram no lugar

Baleia, a cachorrinha,

Fabiano teve que sacrificar

Se não a doença a levaria embora devagar

O salário vinha sempre com uma parte a faltar

Fabiano foi ao patrão questionar

Saia de minhas terras, seu safado

Não te quero mais lá

Fabiano e sua família

Novamente tiverem que partir

Em busca de novo lar

A seca retornava, sem jamais esperar

E essas vidas

Que eram parte do cenário

Só tinham o sertão pra morar

Anexo II - Fanfic

\section{A maldição de São Bernardo}

Na penumbra da noite, o pio das corujas era o único som ouvido naquela clareira. Aquela área era uma terra sagrada para as aves, o lar acolhedor cheio de árvores que compunham seu 


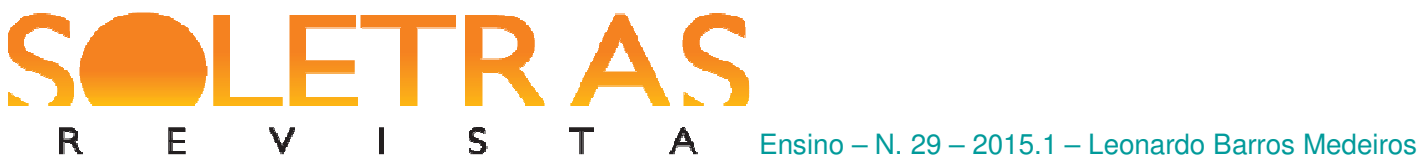

refúgio e diversidade de animais pequenos que serviam como seu alimento. Porém, esse paraíso foi destruído por um humano. Cobiçando riquezas vindas do fértil solo daquele terreno, o homem comprou-o sem saber seu real valor para a população das pequenas aves. Ele e seu fiel companheiro - um cachorro cuja raça nomeou "suas" terras - derrubaram os troncos que abrigavam seus ninhos, e exterminaram suas presas, deixando inviável a vida das corujas.

Mal sabia o homem que acabara de acarretar uma praga, que assombraria cada dono da então fazenda. A consciência deles não seria deixada em paz. Toda noite, vultos percorreriam as plantações quando a observassem. Sons de passos seriam ouvidos, copos e pratos seriam levados ao chão e quebrados. Um pequeno lembrete das mortes causadas.

Porém, com o passar dos anos, a maldição abrandou. Como as corujas tinham conseguido se estabelecer em uma construção da fazenda, o lembrete começou a cessar se resumindo a alguns passos ouvidos em noites ocasionais.

Até o atual dono tomar posse. Sem conseguir se acostumar com o barulho das corujas, o rude homem começou a matá-las, reacendendo sua ira. A chama da vingança ardeu com ainda mais poder, e o espírito das aves fizeram bem mais que quebrar vidro. Eles foram lhe tirando tudo o que ele prezava como as pequenas coisas da vida que antes o atual dono não dava valor, mas já estava sentido falta.

Ele sabia que quando sua esposa via o Padilha ela logo se animava porque eram amigos, mas Paulo se enchia de fúria ao vê-los conversando. Por causa dos maus tratos que ele fazia com Madalena e por causa de seus planos contra Padilha e outros obscuros, a maldição abrasou seu infortúnio.

A morte de sua esposa foi apenas um sinal de que havia sido desencadeada a fúria da maldição, a sua vida entrou em declínio. Não adiantaria o atual dono tentar reparar o erro que cometeu ou o que deixou de fazer. Aos poucos Paulo Honório perdeu suas plantações, o seu gado, aliás, todos os animais morreram, perdeu até a fertilidade de suas terras.

O que houve depois?

-O que isso importa? Já não restava nada da vida de Paulo. Já não restava Paulo. 